\title{
Apristas en Chile: circuitos intelectuales y redes políticas durante los años 1930
}

\author{
Sebastián Hernández Toledo ${ }^{1}$ \\ Recibido: 5 de septiembre de 2014 - Aceptado: 15 de octubre de 2014
}

\begin{abstract}
Resumen
Los circuitos intelectuales y redes políticas que generaron los exiliados apristas en Santiago durante los años 1930 se observan a través de proyectos editoriales, nexos políticos y debates ideológicos en Chile. La hipótesis sostiene que el contexto sociopolítico en el Chile posterior a la dictadura del General Carlos Ibáñez del Campo (1931) hasta el fin del Frente Popular (1941), fue propicio para la construcción de un espacio político e intelectual transnacional de alcance continental y la emergencia de un diálogo entre dos esferas públicas nacionales, la chilena y la peruana, en la que los apristas lograron influenciar y transformar el escenario político-cultural chileno.
\end{abstract}

Palabras clave:APRA, circuitos intelectuales, redes políticas, editorial.

\section{Apra supporters in Chile: Intellectual circuits and political networks for the years of 1930}

\begin{abstract}
The intellectual circuits and political networks that APRA exiles generated in Santiago during the years of 1930 are observed through publishing projects, political links and ideological debates in Chile. The hypothesis says that the sociopolitical context in Chile after the dictatorship of General Carlos Ibáñez del Campo (1930) until the end of the Frente Popular (1941) was suitable for the creation of a transnational political and intellectual space with continental scope and the emergence of a dialogue between two national public spheres, Chile and Peru, where APRA managed to influence and transform the Chilean political-cultural scene.
\end{abstract}

Keywords: APRA, intellectual circuits, political networks, editorial.

Chileno. Magíster en Historia de la Pontificia Universidad Católica de Chile. Becario Conicyt. E-mail: srhernandez@uc.cl 


\title{
Apristas em Chile: circuitos inteletuais e redes políticas durante os anos 1930
}

\begin{abstract}
Resumo
Os circuitos intelectuais e redes políticas que geraram os exilados apristas em Santiago durante os anos 1930's observam-se através de projetos editoriais, laços políticos e debates ideológicos no Chile. A hipótese diz que o contexto sociopolítico no Chile após da ditadura do Geral Carlos Ibáñez del Campo (1930) até o fim do Frente Popular (1941), foi apropriado para a construção de um espaço político e intelectual transnacional de importância c continental e a emergência de um diálogo entre duas esferas públicas nacionais, a chilena e peruana, no qual os apristas lograram influenciar e transformar o cenário político-cultural chileno.
\end{abstract}

Palavras-chave: APRA, circuitos intelectuais, redes políticas, editorial.

Desde 1919 hasta 1930 Perú vivió la extensa dictadura de Augusto Leguía, quien desarrolló entre sus políticas más conocidas la promulgación de la Constitución de 1920, la creación de la Dirección de Asuntos Indígenas, la celebración del "Día del Indio", la excesiva apertura económica con Estados Unidos y varias obras públicas que intentaban legitimar su gobierno y reforzar el culto a la personalidad. Sin embargo, al igual que en la mayoría de los países latinoamericanos, la crisis económica de 1929 repercutió de inmediato en el escenario político peruano, dando fin al oncenio de Leguía, iniciando una década inestable de dictaduras militares y radicalizando a las clases populares representadas en una nueva disyuntiva: comunismo o aprismo (Galindo, 1994: 291).

En 1924 Víctor Raúl Haya de la Torre fundó en México la Alianza Popular Revolucionaria Americana (APRA), partido político que buscó la creación de un Frente Único Indoamericano que luchara contra el imperialismo. Empero, no fue sino hasta 1930, cuando se fundó el Partido Aprista Peruano, que este movimiento tuvo su primera organización política con una base nacional, postulando radicales cambios políticos y sociales a favor de las clases populares. Este partido de clara noción antiimperialista, indoamericanista y de izquierda, tuvo que convivir durante la década del '30 y principios del '40 con las dictaduras de Luis Sánchez Cerro (1931-1933) y Óscar Benavides (1933-1939), así como con los primeros años de gobierno de Manuel Prado (1939-1945), quienes mantuvieron una constante persecución a todos los militantes del APRA, siendo éstos apresados o deportados a distintos países del orbe.

Con la vigencia de la Constitución de 1925 en Chile se produjo un nuevo orden social producto de gobiernos de corte asistencialista y de alianzas políticas tales como el Frente Popular (1937-1941). Esto dio paso a un periodo 
de consenso de mayorías, participación de diversos sectores sociales y una consolidación del sistema burocrático que acabó con la intervención de militares en política, generando un contexto de tranquilidad democrática anómalo en el continente por esos años. Fue esta misma estabilidad social que hizo que Chile se volviera un centro político y cosmopolita para muchos exiliados del continente, haciendo que se asilen en este país varias personalidades de Argentina, Venezuela y, en mayor medida, de Perú, específicamente del APRA, quienes, dada la cercanía con Chile, hicieron de este país su centro de operaciones.

El objetivo del presente artículo es cartografiar las redes intelectuales y políticas que generaron los exiliados apristas en Chile, postulando que éstos lograron influenciar y transformar el escenario cultural y político chileno a través de la Editorial Ercilla y de sus nexos con el Partido Socialista, la implementación del Comité Aprista de Chile y los debates generados con el Partido Comunista respectivamente, lo que finalmente significó que la constante circulación de ideas generaran un nuevo escenario políticocultural en Chile.

\section{Un oasis peruano: La Editorial Ercilla y las publicaciones apristas en Chile}

\section{a. Editorial Ercilla}

Desde inicios de la década del '30 hasta fines del '50 Chile vivió una expansión editorial reforzada por la crisis económica y la posterior Guerra Civil Española, que paralizaron las traducciones europeas e hicieron cada vez más difícil obtener recursos para la compra de libros en el extranjero, teniendo como consecuencia el estímulo de la producción nacional y la creación de nuevas editoriales (Subercaseaux, 2010: 137). De esta manera, en 1928, en plena dictadura de Ibáñez, nació la Editorial Ercilla, posicionándose rápidamente en el ambiente intelectual chileno como la editorial más importante del país. Esta empresa, a cargo de Ismael Edwards Matte, se caracterizó por consolidar la masificación del libro, publicando diversos títulos y colecciones que abarcaran la mayoría de lectores posibles y promoviendo nuevas temáticas como biografías, literatura infantil, novelas policiales, economía, política, manuales caseros y una "Biblioteca Femenina", esfuerzo editorial sin precedentes en Chile.

Dada la relevancia que obtuvo la Editorial Ercilla en Chile, la familia Edwards Mac Clure, dueños del periódico El Mercurio, decidieron formar la empresa Editora Zig-Zag S.A., que tenía por objetivo competir de manera directa con Ercilla. Sin embargo, a pesar de los esfuerzos, durante los años 
'30 la editorial de El Mercurio no pudo sobreponerse a Ercilla; la venta y circulación de variados títulos por el continente de éste último, gracias a su staff aprista y sus contactos latinoamericanos, hizo que los libros tengan una mayor recepción y que más autores quieran publicar a través de esta empresa.

La Editorial Ercilla no tuvo trabajadores peruanos hasta 1934, año en que se radicó en Chile el escritor aprista Luis Alberto Sánchez, quien señaló años más tarde en su libro Visto y vivido en Chile sobre Editorial Ercilla: "rodeada de maleficios, fama y agradecimientos, ella fue [Ercilla], particularmente para los desterrados apristas del Perú, un oasis" (Sánchez, 2004: 57). Después del ingreso de Sánchez a la Editorial, la entrada de más exiliados peruanos no se hizo esperar, siendo contratado el ex diputado Trujillo Américo Pérez Treviño como subcontador, el líder obrero Luis López Aliaga como vendedor, el diputado y empresario de cine Alfredo Baluarte, quien sería vendedor y posteriormente representante de Ercilla en Caracas, el ex decano del Colegio de Abogados de La libertad, Medardo Revilla, como vendedor, al igual que muchos otros (Sánchez, 2004: 58). De mayor renombre fue el equipo traductor de Ercilla, que contó con el escritor Ciro Alegría, el periodista y miembro fundador del APRA Manuel Seoane, el poeta Alberto Hidalgo, el economista Carlos Manuel Cox, el profesor Antero Peralta y como Jefe de Talleres el prestigioso editor limeño Fernando Rosay.

Así, la influencia aprista estuvo constantemente presente en la publicación de títulos, destacando entre ellos los textos de Haya de la Torre El Antiimperialismo y APRA, ¿A dónde va Indoamérica?, así como los miles de ejemplares de Excombatientes y desocupados; de Manuel Seoane, Rumbo argentino y Nuestra América y la guerra; de Ciro Alegría, El mundo es ancho y ajeno; de José Diez Canseco Duque; de Pedro Muñiz, Penetración imperialista; de Luis Alberto Sánchez, Panorama de la literatura actual; entre muchos otros títulos y autores provenientes del APRA. Fue tal la influencia peruana en la editorial que al poco tiempo surgió la crítica chilena, a la que Luis Alberto Sánchez después de enumerar a todos los trabajadores y publicaciones peruanas en Ercilla escribió "con tales antecedentes se comprende que para algunos pequeños de alma y cortos de visión, Ercilla fuese una editorial peruana" (Sánchez, 2004: 59).

Sin embargo, Ercilla no sólo destacó por la publicación de títulos peruanos, sino también por su amplio repertorio europeo y latinoamericano que actualizó las bibliotecas y librerías de Chile. Entre las obras más importantes destacaron Chile o una loca geografía, de Benjamín Subercaseaux; El destino de América Latina, de S. Guy Inman; A través del desastre y Humanismo integral, de Jacques Maritain; On Panta, de Mariano Latorre, entre muchos títulos más (Subercaseaux, 2008: 222). Ercilla, en palabras del mismo Sánchez, llegó a tener un catálogo de 800 títulos y durante 1936 y 1937 publicó 
diariamente un título distinto, entre los que destacaban textos de autores americanos que postularon la unión continental; como el mexicano José Vasconcelos, el peruano Haya de la Torre, el hondureño Rafael Heliodoro Valle o el mismo Sánchez (Sánchez, 2004: 64).

El éxito de Ercilla también se debió a su visión continental, pues ésta, como afirma Subercaseaux, "operaba comercialmente con una perspectiva más latinoamericana e internacional, gracias, en parte, a la numerosa presencia de extranjeros en ella" (Subercaseaux, 2008: 227). La editorial tuvo una gran difusión en el continente debido a que tenía sucursales en Caracas, Buenos Aires, Ciudad de México, San José y Montevideo, así como agentes de venta en las principales ciudades del continente; en definitiva, personas exiliadas pertenecientes al APRA vieron como una opción de trabajo ayudar en la difusión de los títulos de esta editorial.

Finalmente, el criterio empresarial de Ercilla convivió con la difusión del latinoamericanismo, antifascismo, la solidaridad con la República en España y varias visiones del aprismo, lo que se tradujo, como afirma Ricardo Melgar Bao, en que el norte de la Editorial sea la venta de títulos "conciliable con la buena calidad literaria, histórica, filosófica o política de la obra" (Melgar, 2010: 161).

\section{b. Revistas y editoriales de influencia aprista en Chile}

Los cerca de 300 peruanos exiliados que vivieron en Chile entre 1930 y 1945, la mayoría pertenecientes al APRA, no sólo estuvieron presentes en las letras chilenas a través de la Editorial Ercilla, también escribieron en múltiples revistas y periódicos que les permitieron forjar redes intelectuales y alentar debates políticos que causaron ciertas transformaciones en la intelectualidad chilena.

Una revista importante fue Ercilla, perteneciente a la editorial anteriormente mencionada y que a partir de 1936 estuvo dirigida por Manuel Seoane junto a Manuel Solano y Bernardo García Oquendo, todos peruanos y apristas. Esta revista causó alto impacto debido a sus artículos sobre cultura, política y economía, escritos por Salvador Allende, Marmaduke Grove, Óscar Schnake, Eduardo Frei y Pedro Aguirre Cerda, todos ellos amigos cercanos del director y colaboradores asiduos de la revista.

Seoane logró posicionar a la revista Ercilla como la más importante del país gracias a su influencia en círculos políticos y sus múltiples contactos, proponiendo así nuevas ideas en el periodismo chileno como "los enviados especiales", que comenzaron por cubrir el terremoto de Chillán y la Segunda Guerra Mundial para la revista. Sánchez describió el papel que cumplió cada integrante de la revista de la siguiente manera: "[Seoane] Líder aprista, 
periodista de raza, compartió la amistad de Ibáñez y de Allende, de Frei y de Aguirre. La mano de Fabry [gerente y editor de Ercilla] iba convirtiendo día a día a Ercilla en un ente típicamente industrial" , más adelante advertía sobre la primera mujer periodista de Chile y posterior Premio Nacional de Periodismo: "Lenka Franulic preparaba las monografías de sus Cien escritores contemporáneos" (Sánchez, 2004: 65-66).

Los buenos resultados tanto de la revista como de la editorial permitieron a gran parte de los exiliados apristas desarrollar redes con los más importantes literatos del país, generando a través de cafés, tertulias y comidas una amplia circulación de ideas y nuevas lecturas. Entre los nombres de la sociabilidad literaria chileno-peruana destacaron los trabajadores de Ercilla (editorial y revista) y los escritores chilenos Alberto Romero, Rafael Maluenda, Eduardo Barrios, Vicente Huidobro, Pablo Neruda, Gabriela Mistral, Raúl Silva Castro, José Santos González Vera, Mariano Latorre, entre otros.

El Comité Aprista chileno también tuvo relevancia en la escena editorial a través de la publicación de textos políticos en la Editorial Indoamérica, empresa que buscó "recoger, en relativa forma de presentación orgánica, los documentos expositivos y polémicos de la teoría aprista y ofrecerlos al público lector de Indoamérica en una colección de folletos a cómodo precio" (Haya de la Torre, 1933: 64). La Editorial se inició en 1933 con la publicación de la instructiva prestada por Haya de la Torre en el proceso criminal seguido en su contra por el gobierno peruano a causa de la campaña ideológica cumplida por el APRA en el país incaico; sin embargo, desde 1930 el Comité Aprista publicó en Chile a través de imprentas como "El Globo" o la editorial "América Nueva", quienes cumplían el papel difusor de la ideología aprista mientras se desarrolló una editorial propia para los intereses del partido. La idea de Editorial Indoamérica era mostrar al aprismo como el movimiento político más interesante del continente; de ahí, según la misma editorial, "el profundo interés por conocer su arquitectura doctrinaria, tan combatida y calumniada, simultáneamente, por los conservadores de derecha que lo acusan de comunismo disfrazado y por los utópicos de izquierda que lo tildan de fascista" (Haya de la Torre, 1933: 64).

Como la Editorial Indoamérica fue hecha para difundir la ideología aprista, era muy difícil que se mantuviera vigente, por lo que se organizó comercialmente como sociedad de acciones, valiendo cada una de éstas cinco pesos. Posteriormente la editorial informaba: "quienes quieran apoyar esta obra, y participar de sus beneficios económicos, deben dirigirse, en procura de mayores datos, al Gerente de la Editorial Indoamérica"; sin embargo, estaba más que claro que el participar en esta empresa fue más por conciencia política que por buscar un buen negocio (Haya de la Torre, 1933: 65). A pesar de lo anterior, el objetivo de esta editorial se adecuó a un fin latinoamericano que consistió en difundir la ideología del APRA en todo el continente. Para esto, 
diversos personeros apristas generaron una red de publicaciones llamada "Biblioteca Aprista" con la que estaban presentes en Perú, Chile, Argentina, Bolivia, Ecuador, Panamá, Colombia y Francia, publicando documentos políticos del Partido Aprista Peruano, títulos de Haya de la Torre, de Luis Heysen, de Manuel Seoane, de Luis Alberto Sánchez, de Alberto Hidalgo, de Magda Portal, entre otros.

Por otro lado, fueron varios los periódicos y las revistas que solidarizaron con la desaprobación de las dictaduras peruanas otorgando espacios a los exiliados apristas para que participaran con artículos; entre estos destacaban los periódicos La Hora, La Opinión y Frente Popular, así como las revistas Excelsior (también de la Editorial Ercilla), Hoy, Revista Universitaria y Athenea. En ellas se puede apreciar algunos artículos que dieron cuenta sobre el carácter represivo que adquirieron las dictaduras en Perú, como, por ejemplo, el periódico La Opinión, que el 1 de enero de 1935 publicó "El Perú se consume en ola de represión", desarrollando el artículo en base a las declaraciones de los nuevos deportados apristas a Chile que señalaron que "el Gobierno de Benavides [estaba] en plena ofensiva contra la cultura de la nueva generación" 2 .

A partir de 1935 la dictadura de Benavides inició un proceso de búsqueda de apoyo internacional desplegando agentes diplomáticos y periodistas que mejoraran la visión de su gobierno, lo que causó en Chile ciertos roces entre periódicos de derecha como La Nación y El Mercurio contra la revista Ercilla y el periódico Hoy. Esto llegó a su punto más álgido cuando en enero de 1937 se desarrolló en Valparaíso el Congreso Latinoamericano de Prensa, en el que la influencia de los periodistas peruanos Manuel Seoane, Luis Alberto Sánchez, Jorge Muñiz y M. Cabello -todos pertenecientes a la empresa Ercilla- hizo que se aprobara un voto "descalificando moralmente a los periodistas que habían ejercido cargo de censor gubernativo de Prensa", dirigido directamente a los representantes del gobierno peruano Humberto de Águila y Federico More ${ }^{3}$.

Otro elemento que primó en los periodistas apristas fueron las ideas "indoamericanistas", quienes también presentaron un reclamo para "que se le devolviera la libertad a los periodistas perseguidos en Ecuador, Perú y Puerto Rico, y que se permitiese la libre circulación de los periódicos clausurados en esos países" ${ }^{\prime 4}$. De este modo, la influencia aprista en el Congreso no fue

\footnotetext{
"El Perú se consume en una ola de represión". En La Opinión, 1 de enero de 1935.

"Argentinos y Peruanos dieron color polémico al Congreso de Prensa de Valparaíso". En Ercilla, 18 de enero de 1937.
}

4 Ibid. 
menor, liderando los grandes temas a debatir y proponiendo los nuevos intereses de la prensa a nivel continental.

En definitiva, la presencia de los exiliados apristas en una de las editoriales más importantes de Chile como fue Ercilla trajo consigo una reapertura de nuevas lecturas para el país, transformando el campo editorial chileno en una fuerte batalla de publicaciones y búsqueda de lectores. Por otra parte, la constante aparición de artículos de prensa y de literatura sobre temáticas peruanas ayudó a nutrir el ambiente cosmopolita chileno, transformando a la prensa chilena en medios de información y crítica más globalizados y con mayor atención a lo que pasa en el continente. Así, la constante presencia en el ambiente intelectual hizo que los apristas avecindados en Chile entren a la palestra política, ya sea a través de sus redes, debates o sus aportes de reflexión política, hecho que no pudieron obviar los partidos y dirigentes chilenos, entablando diálogos y aportando en un nutrido debate de conceptos y acciones sobre el americanismo y las políticas de izquierda.

\section{EI APRA y la política en Chile}

\section{a. Carlos Vicuña Fuentes y Raúl Haya de la Torre. Los primeros vínculos entre apristas y chilenos}

La influencia aprista también estuvo presente en la política, a través de los contactos y redes que generaron los exiliados peruanos y la circulación de ideas indoamericanistas, antiimperialistas y antifascistas que pregonaron a lo largo del continente. El 6 de febrero de 1933 la Cámara de Diputados de Chile aprobó por unanimidad un voto de petición en favor de la libertad de Haya de la Torre, quien había sido encarcelado en Perú. Esta moción fue pronunciada por el diputado del Partido Social Republicano Carlos Vicuña Fuentes, a quien la Sección Aprista de Chile lo consideraba un "viejo amigo del Perú que su solvencia ética e intelectual estaba fuera de toda discusión" (Haya de la Torre, 1933: 4).

En su discurso, Vicuña Fuentes postuló el carácter continental y a la vez universalista de este tema, mostrando como una obligación de todo el continente pronunciarse sobre este problema, añadiendo: "toda cuestión verdaderamente americana es sin duda una alta cuestión política, y toda cuestión política es indudablemente una cuestión de Humanidad", justificando su referencia sobre el caso peruano (Haya de la Torre, 1933: 5).

Para Vicuña Fuentes la importancia de Haya de la Torre fue el "haberse rebelado en la lucha heroica y desigual contra el gobierno degradado de Leguía, por haber recorrido, desterrado, la Europa y la América predicando 
su evangelio de unión y de fe", que en definitiva destacaba su creencia en el juvenilismo y en el americanismo, conceptos propios del aprismo y que más tarde también tendrían resonancia en Chile ${ }^{5}$.

El diputado Vicuña afirmó que Haya de la Torre fue "el maestro de la juventud de toda América" y que era "una ofensa para todos nosotros que se le mantenga indefinidamente en esta situación de preso" (Haya de la Torre, 1933: 9). Esta cercanía con la juventud que Vicuña Fuentes resaltó en el político peruano data desde 1922, cuando este último al llegar a Chile visitó la tumba de Domingo Gómez Rojas, estudiante y poeta de corriente ácrata, muerto tras un mes de agonía producto de la represión del gobierno de Salvador Sanfuentes en 1920. Fue después de este viaje que el líder aprista resaltó el papel de los jóvenes en la política para generar un nuevo proyecto continental, diciendo: "Creo que hay una distancia enorme entre la juventud del Perú y la que lucha en Argentina, Uruguay y Chile", añadiendo más adelante en su perorata, "yo creo no equivocarme al declarar que existen dos Uruguay, dos Argentina, dos Chile. En cada uno de estos países el pasado y el porvenir están definidos en un dualismo fecundo. El grito que oí en Santiago a un estudiante representativo, condensa la voz de las juventudes del sur del continente: 'iseamos distintos de nuestros padres!'" (Sánchez, 1934: 76).

Por último, Vicuña Fuentes cerró su discurso en el Congreso Nacional resaltando un americanismo de Haya de la Torre que se comprendía también como una unión de resistencia en contra de Estados Unidos; el diputado señaló: "este sentimiento de americanidad, esta necesidad de desarrollar entre nosotros la solidaridad americana, que mañana nos salvará en la lucha inevitable contra nuestra enemiga la raza sajona, es lo que me impele a pedir que la Cámara se interese por este hombre superior" (Haya de la Torre, 1933: 9).

El contacto de Haya de la Torre con el continente y, en específico, con Chile, fue destacado cuando en 1922 valoró más la unión continental que las luchas por territorio existente entre Perú y Chile; según Luis Alberto Sánchez, el dirigente del APRA dijo: "Chileno y vendido al oro chileno me llamó la prensa de Leguía en 1923. Yo sé que un día, como lo dije en Chile en 1922, la unión de nuestros pueblos será una realidad. Entonces, el ridículo

5 El juvenilismo se refiere a una militancia desinteresada a favor de la juventud, en donde hay una preocupación central sobre los jóvenes, así como de las ideologías y pensamientos adheridos a este sector de la sociedad (Pita, 2009). El americanismo se refiere, según José Ingenieros, "a las fuerzas morales que deben actuar, en el sentido de una progresiva compenetración de los pueblos latinoamericanos, que sirvan de premisa a una futura confederación política y económica" (Devés, 2000: 184-185). 
sangriento envolverá a los hombres que han hecho la plataforma política de un odio que jamás han sentido" (Sánchez, 1934: 144).

De este modo, la defensa de Vicuña Fuentes no sólo se basó en una relación de amistad con Haya de la Torre, sino también en una relación política que difundió en Chile posturas centrales como el americanismo y el juvenilismo, lo que sin duda causó influencia en este país y permitió una mejor integración ideológica en el escenario político de los apristas exiliados en Chile.

\section{b. Apristas y Socialistas: sociabilidad política en Santiago}

En 1941 Haya de la Torre envió su mensaje de apoyo a los camaradas desterrados a Chile, argumentando que este país era central porque "es un hospitalario exilio, de donde vino, con el apoyo ilustre de O'Higgins, la gran cruzada de la libertad" (Haya de la Torre, 1941: s/n). Sin embargo, años antes, la recepción fundamental de los apristas en el país la hicieron los socialistas, lo que se relacionó a los conceptos y pensamientos en común que poseían ambas vertientes como el latinoamericanismo y antiimperialismo. Luis Alberto Sánchez señaló que a su arribo a Chile sus primeros visitantes fueron los socialistas Óscar Schnake y Eliodoro Domínguez, quienes pusieron a los apristas "en contacto con los socialistas de Santiago" (Sánchez, 2004: 76).

Seguido a esto, Sánchez se hizo amigo casi de inmediato de Salvador Allende, Luis Henríquez Acevedo y Julio Barrenechea, quienes integraron al escritor peruano y a muchos otros apristas al círculo del Partido Socialista, Ilevándolos, por ejemplo, a la seccional Carlos Marx, ubicada en la calle Nataniel Cox de Santiago, donde podían estrechar vínculos con la futura diputada Carmen Lazo o con el símbolo del socialismo chileno Marmaduke Grove. Frente a esto, Sánchez escribió: "con Salvador recorrí varios locales socialistas y nos reuníamos a conversar en los cafés bohemios de la Alameda y de los portales. Había uno, el de La Puñalada, que se hizo célebre después de 1936, por la presencia en él de muchos españoles refugiados" (Sánchez, 2004: 77-78).

En 1939, con la llegada del Frente Popular al poder, distintos políticos e intelectuales chilenos y latinoamericanos ayudaron a la realización de un festival peruano en el Teatro Comedia de Santiago. Este festival, según afirma Ricardo Melgar Bao, "además de cumplir una función integradora de la variopinta colonia peruana en Santiago, sirviese de vehículo de propaganda antidictatorial, así como de recaudación solidaria de fondos" (Melgar, 2010: 154). Entre los destacados organizadores y participantes del festival se encontraban los chilenos Pablo Neruda, Óscar Schnake, Eduardo Frei y Fernando Maira, 
el peruano Fernando León y el venezolano Rómulo Betancourt. En su texto autobiográfico, Sánchez relató lo siguiente frente a sus amistades políticas:

"mis mejores amigos fueron, sin duda, políticamente, los socialistas. Ya he narrado los encuentros y la convivencia con Schnake, Grove, Allende, Berrenechea, Martínez, Domínguez, Henríquez Acevedo, Bernardo Ibáñez, Tapia, Hübner, Azócar. Tuve muchos amigos radicales, algunos comunistas y algunos conservadores; no dejé de disfrutar de la amistad de los democratacristianos (Frei, Leighton, Torres, Tomic, Tomás Pablo, Palma, Garretón). La mayoría de mis contertulios tenían por oficio pensar por los demás. Fuera de Chile me ocurrió que mis amigos latinoamericanos más numerosos y constantes fueron chilenos: Felipe Herrera, Emilio Edwards Bello, Jorge Millas, Pepe Zañartu, Hernán Santa Cruz, Juan Bautista Rosseti, Alberto Serrano, Salvador Reyes, Arturo Torres Rioseco, Rodrigo Arratia, Fernando Alegría, qué sé yo" (Sánchez, 2004: 210).

La amistad entre apristas y socialistas fue una constante hasta 1973 y aunque la conformación del Frente Popular, la lucha antifascista y el antiimperialismo acercó a los exiliados peruanos a personeros de otras fuerzas políticas, siempre lo más cercano y representativo del aprismo en Chile fue el Partido Socialista. De este modo, Sánchez señaló "la presencia de nuestros compañeros era natural en toda asamblea socialista. Así llegamos hasta la guerra de España, y seguimos unidos, y vino el Frente Popular y nos juntamos más"; más adelante agregaba: "habríamos seguramente sintonizado hasta hoy [1975], si el extremismo verbal de algunos y la terca campaña sovietizante de Fidel Castro no determinan en Allende el brusco y radical cambio de actitud que experimentó, después de su triunfo como Presidente de Chile" (Sánchez, 2004: 81).

Quizás fue este mismo recelo frente al comunismo soviético que hizo que los apristas también se acercaran a círculos intelectuales no partidistas pro-trotskistas, escribiendo sobre antifascismo y antiestalinismo, por lo que nunca se vieron en medios de difusión comunista como la revista Principios o los diarios Bandera Roja, El Comunista o El Siglo.

\section{c. Antifascismo y antiestalinismo. Posturas apristas expuestas en Chile}

Con la creación de la Confederación de Trabajadores de Chile (CTCH) en 1936 se buscó la homogeneización política de la clase obrera a través de la estatización del movimiento obrero, proponiendo un "sindicalismo legal" amparado en las bases legales del Código del Trabajo que reglamentaba su funcionamiento. Esto hizo que las organizaciones obreras quedasen a cargo 
en su mayoría del Partido Comunista de Chile (PCCh), haciendo que su poder de manifestación fuese liderado por las fracciones políticas del Frente Popular, disminuyendo el poder organizacional de disidentes comunistas como los trotskistas y el movimiento anarquista.

Junto al ascenso de Pedro Aguirre Cerda en 1938, la Izquierda Comunista (IC) se disuelve, ingresando la mayoría de sus militantes a las filas del Partido Socialista, en el que varios ex trotskistas desempeñaron un papel importante en el gobierno del Frente Popular, siendo el caso más significativo el nombramiento de Manuel Hidalgo como embajador en México. Otros nombres de importancia como Emilio Zapata, Ramón Sepúlveda y Óscar Waiss apoyaron abiertamente al nuevo gobierno. Por su parte, la minoría de la IC se resistió a la política coalicionista del Grupo Bolchevique Leninista, quienes proclamaban fidelidad a la IV Internacional, desembocando finalmente en la fundación del Partido Obrero Revolucionario en 1937, quienes no apoyaban los postulados nacionalistas expuestos por el Partido Socialista chileno fundado en 1933 (Coggiola, 2006: 407-409).

Bajo este contexto, los apristas Ciro Alegría y Luis Alberto Sánchez se acercaron al director Enrique Espinoza y posteriormente a todo el equipo editorial de la revista Babel (1939-1951), quienes en su mayoría tenían una visión ácrata y antiestalinista de la política; el mayor ejemplo de esto fue su director, quien desde 1938 se transformó en representante literario de Trotsky en Chile 6 . Así, en diciembre de 1937 en el no 7 de la revista SECH, en la que Espinoza fue director antes de asumir Babel, publicó un número homenaje dedicado a la Revolución Rusa, destacando entre sus colaboradores el peruano Luis Alberto Sánchez, quien criticó a la política estalinista de la siguiente manera:

"evidentemente gran parte de la responsabilidad de esa desorientación [política y revolucionaria] corresponde a la III Internacional. La pretensión, primero de 'congelar' el marxismo, como dice Haya de la Torre, en dogmas inconmovibles, asumiendo así una posición antidialéctica; y la decisión en seguida de sumarse a la democracia, halagando lo que ayer se atacara, simplemente por una orden soberana, no presta garantía de fe en la medida rápida y profunda que los secuaces imaginan" (Sánchez, 1937: 7).

El equipo editorial de la revista Babel lo integraron Enrique Espinoza, Laín Diez, José Santos González Vera, Ernesto Montenegro, Manuel Rojas y Mauricio Amster, todos escritores destacados, quienes intentaron plasmar a través de las letras un comunismo libertario antipartidista, poco común en los años 30 y 40. Por su parte, Enrique Espinoza se transformó en representante literario de Trotsky en 1938. Ese año, después de dictar una charla en La Habana llamada "Sobre el contenido social de Martín Fierro", visitó al revolucionario ruso en Coyoacán, donde intercambiaron literatura y establecieron una constante amistad epistolar. 
Claro está que Luis Alberto Sánchez posee una crítica dura al sovietismo, mostrando que "Indoamérica" posee una realidad que "es un hecho con fisonomía propia" por lo que no se podía seguir políticas del otro lado del mundo que no entendían el contexto y las necesidades propias del continente (Sánchez, 1937: 7).

Por último, otros de los tópicos que abordaron los apristas fue el avance del fascismo. Este interés lo expresaban a través de sus redes intelectuales con escritores que se interesaban cada vez más sobre el tema, estando siempre pendiente de la posición política de cada país frente al fascismo y mostrando preocupación de cara a la reacción que desarrolló la gente en torno a estos hechos. Ejemplo de ello es lo señalado por el escritor, periodista y político peruano Ciro Alegría, quien en una carta dirigida a Espinoza manifestó:

"A usted, que está dentro del medio, ¿qué le parece la neutralidad chilena y argentina? Sé que Ríos ha incorporado a su gabinete a ciertos tipos de los que no es posible esperar comprendan el problema. Pienso que esta guerra no es como la pasada y reclama que todos tomen una posición. Pienso que esta guerra tiene una gran proyección histórica y de triunfar el nazismo caeríamos dentro del peor retroceso que el mundo ha conocido. Las democracias pueden haber cometido errores, ayer y antes de ayer, pero es necesario apoyarlas. Yo creo que el nazismo esclavizaría a todos, a todos nuestros pueblos, sin tener en cuenta si han sido neutrales o no. ¿Usted no piensa lo mismo? En trance tal, toda bizantina discusión está fuera de lugar en este momento. Creo que debemos cooperar a la derrota del nazismo, el que entiende claramente que se juega su supervivencia y peleará como un perro rabioso antes de rendirse; me parece que es lo menos que podemos hacer. Esos viejos políticos de Chile creen posiblemente que Hitler le va a premiar su neutralidad con una sonrisa y los cincuenta mil o más alemanes que viven allá, por el mismo motivo, se van a quedar tranquilamente donde están. Estas son cosas que parecen inconcebibles y sin embargo suceden"7.

A partir de lo anterior, Alegría expuso su preocupación por los acontecimientos desarrollados a nivel mundial, vinculándolos a la acción política que se desenvolvía específicamente en cada país. Esta imbricación entre la política interna y externa comenzó a preocupar a los apristas, generando críticas no sólo al fascismo y al estalinismo, sino que también a las políticas que llevaba a cabo cada gobierno en relación con lo sucedido.

Carta de Ciro Alegría a Enrique Espinoza. 6 de julio de 1942. Fondo Glusberg. 


\section{El debate del teatro Setiembre. Desencuentros entre la Sección Chilena del APRA y el Partido Comunista de Chile}

Desde 1931 el PCCh vivió un proceso de bolchevización en que seguía dogmáticamente el programa político de la URSS, factor que generó fraccionamiento entre los comunistas pro soviéticos y los demás partidos de centro-izquierda de Chile. Parte de estas desavenencias políticas recién se atenuaron a partir de la invasión de las tropas nazis a la URSS en 1941, lo que junto con un clima de entendimiento sostenido en las coaliciones antifascistas hicieron que existiese un mejor entendimiento entre comunistas y los demás partidos que integraban el Frente Popular. Por último, la disolución de la Tercera Internacional en 1943 acabó con la rivalidad entre el latinoamericanismo de los socialistas y el internacionalismo de los comunistas, generando una mayor aceptación del PCCh en la palestra política, incluyéndolos en la candidatura de Juan Antonio Ríos (1942-1946) (Moulian, 2010: 98). A partir de esto, la coalición partidista de centro-izquierda se basó principalmente en la construcción de una unidad antifascista y en un gobierno enfocado a las clases medias y bajas, omitiendo el apoyo comunista a Stalin, hecho que sí trajo debates y distanciamientos con los apristas que residieron en Chile durante los años 30.

En 1932, en el teatro Setiembre de Santiago, se realizó un debate ideológico entre el PCCh y la Sección Chilena del APRA, el que atrajo mucha gente, según la crónica de Seoane, "todas las localidades ocupadas, incluso los pasillos" (Seoane, 1933: 7).

Sin embargo, el encuentro se transformó en un gran desorden, pues, como advierte el mismo autor, "la Mesa Directiva [del debate] se negó a conceder el uso de la palabra al estudiante aprista Hernán Boggio", lo que terminó en una batahola donde "ambos bandos se golpearon fuertemente" (Seoane, 1933: 8). Todo esto fue publicado un año después, en el que Seoane describió todo lo acontecido en este debate, señalando que este encuentro se realizó porque "un grupo de comunistas chilenos desafió a polemizar públicamente al Comité Aprista Peruano de Santiago" (Seoane, 1933: 9).

Dado que la polémica terminó entre golpes y gritos, no se pudo sacar mucho en limpio, por lo que Seoane, quien había hecho un monólogo durante el encuentro, decidió publicar su discurso integrando citas de Marx, Lenin y Haya de la Torre para otorgar solidez a sus argumentos, justificando así su postura aprista y marcando la diferencia con el PCCh. El opúsculo de Seoane, llamado Comunistas criollos, se inicia con una cita muy ofensiva en contra de los adherentes de la URSS: "los comunistas criollos se creen o se llaman ultra-revolucionarios. Pero, en realidad, son como los rabanitos, rojos 
por fuera y blancos por dentro" (Seoane, 1933: 7). La anterior cita extraída del periódico socialista La Vanguardia da muestra del debate continental que se estableció entre los Partidos Comunistas y otros grupos de izquierda en que el APRA no se quedó al margen.

La ofensiva aprista por parte de Seoane en contra de los comunistas chilenos partió haciendo referencia a la inaplicación de la teoría marxista en el continente, lo que debía llevar a pensar en nuevos ejes programáticos acordes a las necesidades de cada lugar. Frente a esto, el político peruano escribió: "yo no soy anticomunista. Simplemente no soy comunista. Creo que el comunismo, teóricamente, es un sistema perfecto. Pero creo, también, que ahora es inadaptable a Indoamérica"; más adelante agregó, "traicionaría mi deber social si no lo dijera y procurara probarlo. Por eso, también, milito en las filas del movimiento de justicia y nacionalismo antiimperialista que el aprismo propugna para todo Indoamérica" (Seoane, 1933: 6). Siguiendo la línea de la especificidad de Latinoamérica, el orador peruano fue describiendo en medio de gritos y pifias, según él mismo señala, los argumentos diferenciadores en el aprismo y la política que siguió el PCCh.

Uno de los argumentos descritos por Seoane fue el policlasismo que representó el APRA en su programa político, nutriéndose de una preocupación por el individuo oprimido mucho más amplia que el marxismo, ya que no sólo centró su ideología en el obrero concientizado, sino que en todo sujeto que sufría explotación, como los campesinos, las mujeres y las clases medias. El miembro fundador del aprismo expuso: "digamos, ante todo, que el aprismo no propugna la preeminencia de una sola clase en el gobierno, sea la media, la campesina o la proletaria, sino la conjunción de las clases oprimidas por el imperialismo para dirigir el Estado en el sentido de defensa de sus intereses" (Seoane, 1933: 11).

Seoane aprovechó el teatro y la instancia del debate para repetir una y otra vez las diferentes visiones de la política entre comunistas y apristas, enfatizando en que estos últimos se esforzaban por hacer un análisis detallado y responsable de los problemas del continente, mientras los comunistas sólo copiaban la teoría europea. El líder aprista indicó: "de aquí nace nuestra profunda diferencia con los comunistas criollos. El aprismo procura descubrir la realidad agotando sus esfuerzos interpretativos porque lo inspira una voluntad tenaz de realizar. El comunismo criollo se limita a repetir los textos europeos porque sólo lo mueve un vago deseo de agitar sin construir" (Seoane, 1933: 13).

Siempre fiel a su línea argumentativa, Seoane explicó que la Revolución Rusa era inaplicable en el continente, que desde 1918 hasta 1921 los soviéticos vivieron una gran depresión económica y hambruna, en cambio Latinoamérica debía hacer frente al capitalismo con políticas económicas 
radicales, y que se debía planificar una revolución responsable y no como lo pensaban los "comunistas criollos". Con esto, Seoane hacía alusión a la irresponsabilidad de los comunistas que trabajaron por la revolución inmediata, que incluso, meses antes del debate, en la República Socialista de Marmaduke Grove, se ocuparon de crear soviets en la Universidad de Chile en vez de apoyar el movimiento socialista que se intentó implantar. Frente a la terquedad de los "comunistas criollos" de buscar la revolución sin importar las consecuencias, hemos decidido exponer una cita de Seoane más extensa de lo habitual, ya que ésta deja claro el análisis que hacían los apristas de los movimientos revolucionarios:

"uno de nuestros atacantes [comunista] ha dicho, más o menos: 'no importa que si estalla la revolución comunista nos ataquen los imperialismos porque entonces todos los obreros de Indoamérica se armarán y defenderán la revolución'. Esta frase prometedora le valió muchos aplausos. Pero sometámosla al rigor del análisis. Ataque y defensa suponen guerras y la guerra es un problema de armas y dinero. Para defenderse de los cañones y fusiles se necesitan fusiles y cañones. No tenemos dinero para comprarlos ni lo venderían en el caso de que se trata. No tenemos fábricas de armas. Nuestra inferioridad bélica es evidente. ¿Con qué se armaría a los obreros? ¿De dónde saldrían los cañones, las ametralladoras, los fusiles, las municiones? ¿O es que se creen que esas armas van a salir del suelo como si fueran una cosecha de rábanos?

Sintetizando este análisis, vemos que si la lucha contra el imperialismo es un problema de fuerza es necesario mirar realistamente y adoptar una táctica que, sin envolver la renuncia de los objetivos de nuestra lucha antiimperialista, esté libre de un fracaso" (Seoane, 1933: 31-32).

Las palabras de Seoane no sólo dieron cuenta de las diferencias ideológicas que sostuvieron apristas y comunistas en el continente, sino que también muestran cómo en Chile se generó un escenario de discusión ideológica en el cual los apristas pudieron exponer sus ideas, representando un espacio, dentro del plano político chileno, importante para una izquierda ecléctica que nació por esos años, como fue el Partido Socialista.

\section{Consideraciones Finales}

Los exiliados apristas en Chile forjaron una carrera política e intelectual de gran importancia para el país, representada en editoriales, gestión de proyectos culturales, redes políticas y difusión ideológica, que desarrolló un protagonismo político cultural ascendente en Chile, adquiriendo gradualmente importancia en torno a la cultura y el debate político. Del mismo modo, 
gracias a la conformación de redes político-intelectuales y la importancia que fueron adquiriendo sus trabajos editoriales en el plano cultural, los exiliados peruanos lograron desarrollar paulatinamente un proceso intelectual en el que se conformó una cultura política en torno a las ideas apristas, viéndose plasmadas en sus revistas, discursos e ideas, que llegaron a nutrir el enfoque ecléctico que las nuevas izquierdas estaban adquiriendo en Chile, formulando un ideario más combativo a las políticas privativas y autoritarias reflejadas en el contexto mundial, así como mostró un vuelco hacia las ideas bases del latinoamericanismo y el antifascismo, en boga por esos años.

De esta manera se desarrolló la construcción de un espacio político e intelectual transnacional de alcance continental y la emergencia de un diálogo e interconexión entre dos esferas públicas nacionales, la chilena y la peruana.

Los apristas, por su parte, crearon, a través de su obra, una comunidad imaginada, un espace de sens más amplio que el Estado nacional, lo que tuvo una consecuencia doble: facilitó su integración y aceptación en Chile (ya que no se aplicaron o se aplicaron menos las categorías y distinciones nacionales) y permitió a los intelectuales y una parte de la clase política chilena sentir que formaban parte de una comunidad más amplia que la nacional, lo que creó las condiciones ideológicas e identitarias propicias a su participación en redes transnacionales.

Sin lugar a dudas, la presencia de exiliados apristas en Chile fue muy importante, pues a través de sus diversas actividades generaron nuevos espacios de sociabilidad y de traspaso de ideas, que las historiografías nacionales, la chilena o la peruana, no han recogido. Bien lo decía Neruda cuando motivaba a Luis Alberto Sánchez para que escribiese sobre Chile: "tú tienes una deuda con Chile [...] sólo me refiero a una deuda literaria y política, ustedes los peruanos no saben la influencia que ejercieron tanto en la política como en la cultura de Chile. Desde Ercilla, en los periódicos, en los grupos, hicieron mucho" (Sánchez, 2004: 21).

\section{Referencias Bibliográficas}

\section{Fuentes Primarias}

\section{a. Publicaciones periódicas}

Revista Ercilla, Santiago, 1935-1936.

Revista SECH, Santiago, 1937.

Periódico La Opinión, Santiago, 1935-1936. 


\section{b. Impresos}

HAYA DE LA TORRE, V. (1933). Instructiva Secreta a V. R. Haya de la Torre. Santiago de Chile: Editorial Indoamericana.

HAYA DE LA TORRE, V. (1941). Mensaje del Líder Americano Haya de la Torre a Chile y a los camaradas desterrados. Santiago de Chile: Comité Aprista Peruano de Santiago.

SÁNCHEZ, L. (1937). La Revolución Rusa. SECH, n. 7, 1937. p. 4-10.

SÁNCHEZ, L. (2004). Visto y vivido en Chile. Santiago de Chile: Editorial Tajamar. (1Edición, 1975).

SÁNCHEZ, L. (1934). Raúl Haya de la Torre o el político: crónica de una vida sin tregua. Santiago de Chile: Ediciones Ercilla.

SEOANE, M. (1933). Comunistas criollos. Disección polémica de la charlatanería roja. Santiago de Chile: Editorial Indoamérica.

\section{Fuentes secundarias}

COGGIOLA, O. (2006). Historia del trotskismo en Argentina y América Latina. Buenos Aires: Ediciones RyR.

CRUZ, L. (2002). La República Socialista del 4 de junio de 1932. Santiago de Chile: Ediciones Tierra Mía.

FLORES GALINDO, A. (1994). Obras Completas I. Lima: Sur.

MALDONADO, C. (1988). Entre reacción civilista y constitucionalismo formal: las fuerzas armadas chilenas en el período 1931-1938. Santiago de Chile: FLACSO.

MELGAR BAO, R. (2010). "El exilio intelectual aprista en Chile", en Historia de los intelectuales en América Latina. II. Los avatares de la "ciudad letrada en el siglo XX. Buenos Aires: Katz Editores. p. 146-166.

MOULIAN, T. (2009). Contradicciones del desarrollo político chileno, 1920-1990. Santiago de Chile: LOM Ediciones.

MOULIAN, T. (2010). Fracturas. De Pedro Aguirre Cerda a Salvador Allende (19381973). Santiago de Chile: LOM Ediciones.

PITA, A. (2009). La Unión Latino Americana y el Boletín Renovación. Redes intelectuales y revistas culturales en la década de 1920. Ciudad de México: CEH.

SUBERCASEAUX, B. (2010). Historia del libro en Chile. Desde la Colonia hasta el Bicentenario. Santiago de Chile: LOM Ediciones.

SUBERCASEAUX, B. (2008). "Editoriales y círculos intelectuales en Chile", en Revista Chilena de Literatura, № 72, p. 221-223. 